\title{
ESTUDO DOS MECANISMOS GENÉTICOS E CELULARES DURANTE A FASE INFLAMATÓRIA DO PROCESSO DE REGENERAÇÃO TECIDUAL EM ANIMAIS SELECIONADOS GENETICAMENTE PARA A MÁXIMA RESPOSTA INFLAMATÓRIA AGUDA HOMOZIGOTOS PARA OS ALELOS $R$ OU S DO GENE SIc11a1
}

\author{
Dissertação apresentada ao Programa \\ de pós-Graduação em Imunologia do \\ Instituto de Ciências Biomédicas da \\ Universidade de São Paulo, para \\ obtenção do Título de Mestre em \\ Ciências Biológicas. \\ Área de concentração: Imunologia \\ Orientador: Dr. Marcelo De Franco
}




\section{RESUMO}

CANHAMERO, T. Estudo dos mecanismos genéticos e celulares durante a fase inflamatória do processo de regeneração tecidual em animais selecionados geneticamente para a máxima resposta inflamatória aguda homozigotos para os alelos $R$ ou $S$ do gene S/c11a1. 2009. 91 f. (Mestrado em Imunologia) - Instituto de Ciências Biomédicas, Departamento de Imunologia, Universidade de São Paulo, São Paulo, 2009.

Sublinhagens de camundongos AIRmax e AIRmin homozigotas para os alelos $R$ ou $S$ do gene S/c11a1 apresentam distinta capacidade regenerativa à perfuração de suas orelhas. Animais AIRmax ${ }^{S S}$ exibiram regeneração tecidual precoce em comparação aos animais $\operatorname{AIRmax}^{R R}$, sugerindo que 0 alelo $S$ favoreceu a regeneração nestes animais. Camundongos das sublinhagens AIRmin não apresentaram regeneração após perfuração de suas orelhas. Em resposta ao estímulo, animais AIRmax ${ }^{S S}$ exibiram inflamação local mais intensa e tardia do que animais AIRmax ${ }^{R R}$, demonstrando elevados níveis de MPO e edema, e influxo celular predominantemente de neutrófilos. Ensaios de expressão gênica global demonstraram genes diferencialmente expressos entre as sublinhagens, evidenciando genes sobre-representados no tema biológico proliferação celular em ambas sublinhagens, enquanto somente nos animais AIRmax ${ }^{\text {SS }}$ ocorreu sobre-representação para resposta inflamatória nos genes ativados e para contração muscular nos genes reprimidos. Os resultados de microarray foram validados por qPCR.

Palavras-chave: Resposta inflamatória. Reparo tecidual. Regeneração tecidual. Gene S/c11a1. Blastema. Regeneração epimórfica. 


\begin{abstract}
CANHAMERO, T. Study of genetic and cellular mechanisms during the inflammatory phase of tissue regeneration process in animals genetically selected for maximum acute inflammatory response homozygous for SIc11a1 $\boldsymbol{R}$ and $\boldsymbol{S}$ alleles. 2009. 91 p. Master Thesis (Immunology) - Instituto de Ciências Biomédicas, Departamento de Imunologia, Universidade de São Paulo, São Paulo, 2009.
\end{abstract}

Homozygous AIRmax and AIRmin sublines for S/c11a1 $R$ and $S$ alleles present distinct regenerative capacity to the ear hole. AIRmax ${ }^{S S}$ mice exhibited early tissue regeneration compared to $A_{\text {IRmax }}^{R R}$ animals, suggesting that the S/c11a1 $S$ allele promotes regeneration in these animals. AIRmin sublines didn't show regeneration after ear punch. In response to the stimulus, AIRmax ${ }^{S S}$ animals exhibited more intense and later local inflammation than AIRmax ${ }^{R R}$ animals, presenting elevated levels of MPO, edema and cellular influx predominantly of neutrophils. Global gene expression analysis showed differentially-expressed genes between the sublines, in which over-represented biological theme is cell proliferation in both sublines. AIRmax ${ }^{S S}$ animals displayed overrepresentation of inflammatory response in up-regulated genes and of muscle contraction in down-regulated genes. Microarray results were validated by using quantitative PCR.

Key words: Inflammatory response. Tissue repair. Tissue regeneration. Slc11a1 gene. Blastema. Epimorphic regeneration. 


\section{INTRODUÇÃO}

A resposta biológica a uma injúria é caracterizada por duas categorias distintas: reparo tecidual e regeneração do órgão lesado (CLARK et al., 1998).

O reparo tecidual é um processo complexo que consiste em três fases distintas: 1) fase inflamatória (0-2 dias); 2) formação de novos tecidos (5-20 dias); 3) e um estágio de remodelação (>21 dias), no qual juntas, envolvem a participação de muitos genes (LI et al., 2001; DOVI et al., 1999; SINGER et al., 1999; MARTIN, 1997).

Durante uma lesão, freqüentemente ocorre o rompimento de vasos sangüíneos seguido pela entrada de constituintes do sangue para dentro da injúria, e ainda, mecanismos de vasoconstrição que irão corroborar para a homeostase do tecido e início da fase inflamatória em resposta a injúria. Além disso, a injúria endotelial resulta na ativação de plaquetas que ativam a cascata de coagulação iniciando a formação de uma matriz de fibrina, permitindo provisoriamente a migração celular (TSIROGIANI et al., 2006) (Figura 1A).

Outro mecanismo ativado no início da resposta contra uma injúria é a via do ácido araquidônico. Esta via induz a produção de tromboxana A2 favorecendo a vasoconstrição e o agrupamento de plaquetas, e ainda a produção de prostaciclina (PGI2) promovendo a vasodilatação dos capilares. A vasodilatação também pode ocorrer devido à ação de histamina liberada no local da lesão por mastócitos ativados. Pesquisadores demonstraram a importância destas células durante todo o processo de reparo tecidual, ou seja, na liberação de mediadores químicos como histamina, serotonina, de citocinas como TNF-a, no recrutamento de leucócitos, e ainda na conversão de fibroblastos em miofibroblastos (TSIROGIANI et al., 2006; WELLER et al., 2006).

A desgranulação das plaquetas infere na liberação de grânulos alfa que secretam fatores de crescimento como: epidermal growth factor 
(EGF), platelet-derived growth factor (PDGF) e transforming growth factor- $\beta$ (TGF- $\beta$ ) (BARRIENTOS et al., 2008). O PDGF, juntamente com citocinas pró-inflamatórias como a interleucina 1 (IL-1), são importantes na quiomiotaxia de neutrófilos para o local da injúria (HANTASH et al., 2008).

Os neutrófilos são as primeiras células nucleadas a infiltrar a injúria, e iniciam a descontaminação dessa região destruindo microrganismos invasores, quando houver, e minimizando a possibilidade de uma infecção. Além disso, produzem substâncias bioativas e proteases, que podem converter citocinas que atuam na injúria em uma forma ativa ou inativa, podendo assim interferir na lesão tecidual (DOVI et al., 2004) (Figura 1A).

Macrófagos também participam do processo de reparo tecidual. Após 2 a 3 dias de injúria, monócitos do sangue migram para os tecidos, se ativam, e diferenciam-se em macrófagos, atuando durante todas as fases do reparo tissular, mas o papel tanto destas células, como o de neutrófilos neste processo ainda é pouco conhecido (GURTNER et al., 2008). Estudos demonstram que estas células produzem fatores de crescimento que estimulam a angiogênese e a fibrinogênese (LEIBOVICH e ROSS, 1975; DANON et al., 1989), e desempenham grande importância na remoção de neutrófilos apoptóticos (DOVI et al., 2004). Participam também como um "sensor de patógenos" executando um papel importante no início da resposta inflamatória, na eliminação de patógenos, na resposta imune adaptativa e no reparo dos tecidos prejudicados. Estão presentes na maioria dos tecidos, onde são responsáveis por numerosos processos inflamatórios, imunológicos e metabólicos (PLOWDEN et al., 2004). Além de todas as funções já descritas, macrófagos também secretam citocinas, quimiocinas, fatores de crescimento e enzimas em resposta a patógenos e sinais que indiquem "perigo". Estes incluem citocinas como interleucina 1alfa e beta (IL1- $\alpha$ e $\beta$ ), IL-6, IL-10, IL-12, IL15, IL-18, tumor necrosis factor-a (TNF-a), interferon alfa e beta (IFN-a e 
$\beta)$, TGF- $\beta$, granulocyte-macrophage colony stimulating factor (GM-CSF), macrophage-colony stimulating factor (M-CSF), e fatores angiogênicos como o vascular endothelial growth factor (VEGF), quimiocinas CXC (IL$8)$, growth-related oncogene (GRO), interferon $-y$ - inducible protein 10 (IP-10), fatores de coagulação, prostaglandina E2 (PGE2), leucotrienos, intermediários reativos do oxigênio e nitrogênio, componentes do complemento, e várias enzimas e proteases). A secreção destes fatores depende do tipo de estímulo, do tipo e localização do macrófago (PLOWDEN et al., 2004).

O impacto da resposta inflamatória local no processo de reparo e regeneração tecidual foi debatido por décadas. A participação de macrófagos ou granulócitos promovendo ou impedindo o reparo tecidual tem recebido muita atenção (EMING et al., 2007). Estudos sugerem que neutrófilos podem inibir o processo de reparo tecidual, embora forneçam proteção contra infecções produzem uma variedade de fatores de crescimento que podem promover a revascularização e reparo do tecido injuriado, como IL-8 e VEGF, contudo, outros estudos sugerem que a reepitelização da lesão é favorecida após a depleção de neutrófilos. Além disso, sinais liberados por estas, e outras células inflamatórias podem interferir na migração de queratinócitos e fibroblastos resultando em uma cicatrização não favorável e aumentando a fibrose (DOVI et al., 2004; DOVI et al., 2003; RENNEKAMPFF et al., 2000; MCCOURT et al., 1999; MURATA et al., 1997; LINARES, 1996; BORDER e NOBLE, 1994).

A produção de todos os fatores mencionados acima, como também de proteinases produzidas por estas células inflamatórias, é necessária também na próxima fase do processo de reparo, a formação de novos tecidos (SCHÄFER e WERNER, 2008).

Este estágio ocorre no período de 2 a 10 dias após a injúria e é caracterizado por proliferação celular e migração de diferentes tipos celulares, envolvendo a migração e hiperproliferação de queratinócitos na margem da injúria, permitindo o início do processo de cobertura da lesão 
com uma nova epiderme, processo esse chamado de re-epitelização e, concomitantemente a este processo, o reparo da derme também é iniciado (SCHÄFER e WERNER, 2008; GURTNER et al., 2008). Em seguida, vasos sanguíneos surgem na margem da lesão e também o desenvolvimento de uma nova vasculatura, iniciando a angiogênese. Os principais reguladores positivos da angiogênese são: VEGF-a e o fibroblast growth factor 2 (FGF2) (GURTNER et al., 2008; WERNER e GROSE, 2003). Nesta fase, fibroblastos migram para o interior da lesão, onde proliferam e produzem grandes quantidades de matriz extracelular (ECM). Além disso, alguns fibroblastos se diferenciam em miofibroblastos no qual são responsáveis pela diminuição da lesão e pela deposição adicional de matriz, formando então o chamado tecido de granulação (SCHÄFER e WERNER, 2008; OPALENIK e DAVIDSON, 2005) (Figura 1B).

Os fibroblastos tornam-se o tipo celular predominante do dia 7 ao 14 do processo de reparo tecidual. Neste período, eles iniciam a produção de FGF, TGF- $\beta$, PDGF, bem como de keratinocyte growth factor (KGF) e insulin-like growth factor (IGF) facilitando a síntese da matriz (TSIROGIANI et al., 2006).

O tecido de granulação é composto por células endoteliais, fibroblastos, macrófagos, linfócitos e uma nova matriz extracelular. Os macrófagos ativados liberam PDGF, TGF- $\beta$, e FGF que estimulam os fibroblastos a sintetizarem glicosaminoglicanos, proteoglicanos e colágeno para a constituição da nova matriz extracelular (GREILING e CLARK, 1997).

A fase final, de remodelamento, é iniciada 2 a 3 semanas após a injúria e permanece por um ano ou mais. Neste período, ocorre uma transição de tecido de granulação em tecidos maduros com cicatriz (GURTNER et al., 2008; SCHÄFER e WERNER, 2008).

Durante este estágio, todos os processos que foram ativados por conta de uma injúria entram em declínio e cessam, e a maioria das células endoteliais, macrófagos e miofibroblastos presentes sofrem apoptose ou 
saem da lesão deixando uma massa contendo poucas células, que consiste principalmente de colágeno e outras proteínas de matriz extracelular (GURTNER et al., 2008). A degradação de colágeno é dependente de enzimas proteolíticas específicas conhecidas como metaloproteinases de matriz (MMP), estas enzimas são produzidas por algumas células como, macrófagos, queratinócitos e fibroblastos (TSIROGIANI et al., 2006; ANGELOV et al., 2004; WU et al., 2000). No entanto, o remodelamento continuará por mais de 12 meses, embora as cicatrizes nunca recuperem a resistência de uma derme normal (MONACO e LAWRENCE, 2003) (Figura 1C).
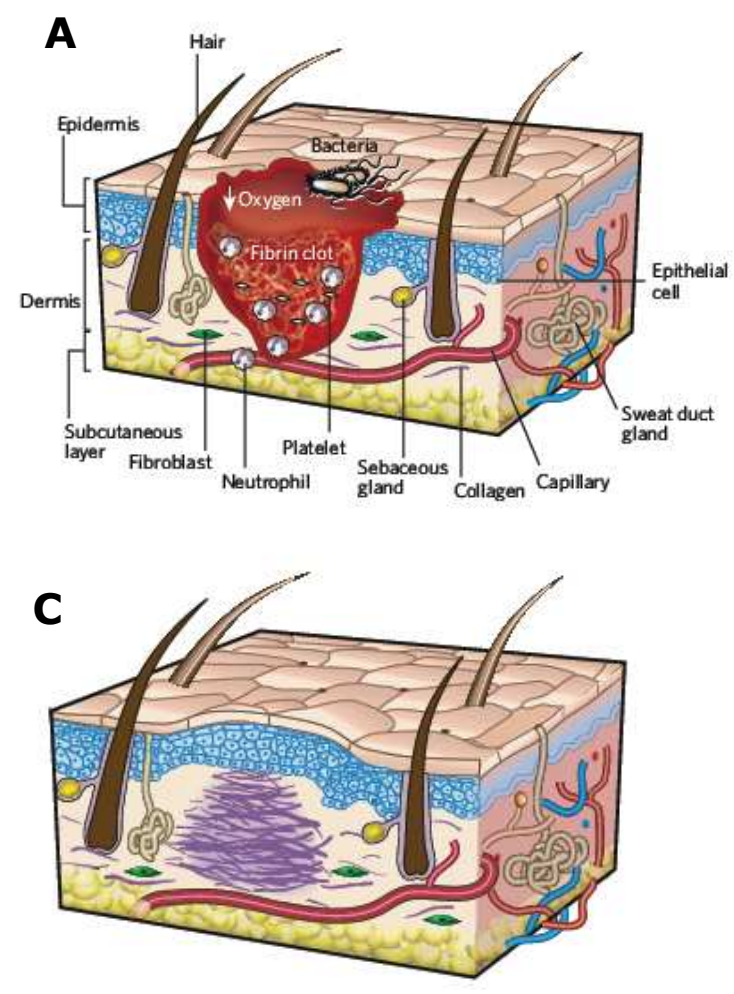

B

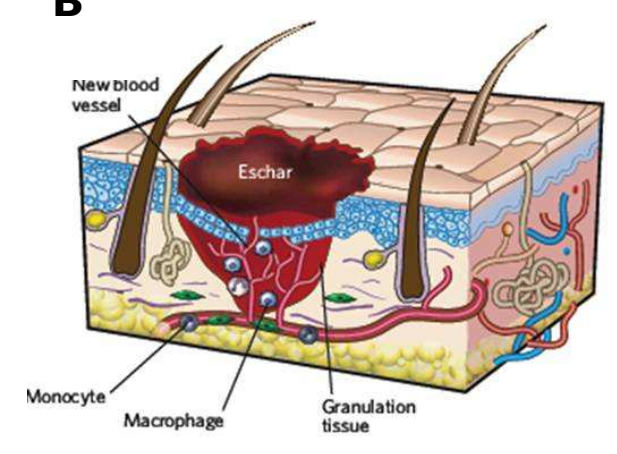

Gurtner et al., Nature; 2008.

Figura 1: Estágios clássicos durante o processo de reparo tecidual: (A) inflamação, (B) formação de novos tecidos e (C) remodelamento.

Estudos avaliando os mecanismos envolvidos no reparo tecidual estão sendo desenvolvidos. Um destes estudos mostra que a deficiência de complexo principal de histocompatibilidade II (MHC-II) compromete o 
reparo tissular, refletindo em um impedimento na função de células imunes e na diminuição da atividade de fibroblastos na injúria (SCHÄFFER et al., 2006). Por outro lado, Eming e colaboradores (2007) investigaram camundongos deficientes de interleucina 10 (IL-10), estes apresentaram uma regeneração acelerada no ferimento. Na injúria dos animais nocaute para a IL-10 havia mais macrófagos em relação à injúria dos camundongos normais controle, e formaram-se muitas células no tecido de granulação (EMING et al., 2007). Outro tema interessante estudado refere-se à relação entre $o$ processo de reparo tecidual e o desenvolvimento de câncer e, ainda, o envolvimento de receptores tipo Toll-like (TLRs) na relação entre o processo de reparo tecidual e carcinogênese (RAKOFF-NAHOUM e MEDZHITOV, 2009; SCHÄFER e WERNER, 2008).

Embora estudos com Biologia Molecular e Celular tenham explicado alguns dos processos biológicos que estão envolvidos no reparo e na regeneração tissular, ainda hoje sabemos pouco sobre este tema complexo nos quais estão envolvidos muitos genes (HEBER-KATZ, 1999; SINGER et al., 1999; ROTHE e FALANGA, 1992).

O mecanismo comumente estudado em tecidos de mamíferos após uma lesão é o reparo, pois a capacidade de regeneração nestes, é limitada ou não existente (HEBER-KATZ et al., 2004; STOCUM, 1996). Contudo, existem vários exemplos de regeneração epimórfica em mamíferos, regeneração esta, anteriormente observada apenas em anfíbios em que os membros foram completamente regenerados após amputação (STOCUM, 1984; GOSS e GRIMES, 1975).

O processo de regeneração, diferente do reparo, envolve uma completa substituição e restauração dos tecidos, exibindo estrutura e funções normais, incluindo condrogênese (RAJNOCH et al., 2003).

Os primeiros mamíferos que exibiram regeneração epimórfica foram os coelhos. Estes animais regeneraram pequenas perfurações induzidas 
experimentalmente em suas orelhas exibindo regeneração semelhante à observada em anfíbios (GOSS e GRIMES, 1975).

No ano de 1998, Clark e colaboradores descobriram um modelo murino, a linhagem de camundongo isogênica MRL/Mpj, que foi capaz de regenerar um orifício de $2 \mathrm{~mm}$ de diâmetro em suas orelhas no período de 30 dias, apresentando todas as características regenerativas, ou seja, a formação de blastema (estrutura tecidual que contém células-tronco mesenquimais indiferenciadas, observada em lesões de anfíbios), a cobertura total da injúria, formação de nova cartilagem da orelha e função tecidual normal, quando comparados à outras linhagens de camundongos isogênicas como C57BL/6 (B6), CAST/Ei, e SJL/J (SJL) que apresentaram apenas reparo parcial de suas orelhas (YU et al., 2005; CLARK et al., 1998; MCBREARTY et al., 1998). Alguns estudos desenvolvidos contribuíram na identificação de vários QTL envolvidos neste fenótipo, indicando que a regeneração em camundongos deve-se a um fenótipo quantitativo controlado geneticamente (MASINDE et al., 2001; CLARK et al., 1998; MCBREARTY et al.,1998).

Recentemente, Reines e colaboradores descreveram que camundongos C57BL/6 (B6) de meia idade aumentam sua capacidade regenerativa com o passar do tempo apresentando regeneração tecidual comparável à dos camundongos MRL (REINES et al., 2009).

As linhagens de camundongos selecionadas geneticamente em nosso laboratório para a máxima (AIRmax) ou mínima (AIRmin) resposta inflamatória aguda (AIR) (IBAÑEZ et al., 1992), apresentam-se como um modelo experimental muito interessante para o estudo dos mecanismos genéticos e celulares envolvidos na regeneração tecidual. Estes modelos foram obtidos através de seleção genética bidirecional, iniciada a partir de uma população fundadora geneticamente heterogênea (F0) produzida através do intercruzamento de oito linhagens de camundongos isogênicas de origem independente (STIFFEL et al., 1990), estas são: A/J, DBA/2J, $\mathrm{P} / \mathrm{J}, \mathrm{SWR} / \mathrm{J}, \mathrm{SJ} / \mathrm{J}, \mathrm{CBA} / \mathrm{J}, \mathrm{BALB} / \mathrm{C}$ ] e C57BL/6J. Cada camundongo da F0 é 
caracterizado por uma recombinação distinta de $12,5 \%$ do pool de genes de todas as linhagens isogênicas originais (IBAÑEZ et al., 1992), conforme esquema abaixo:

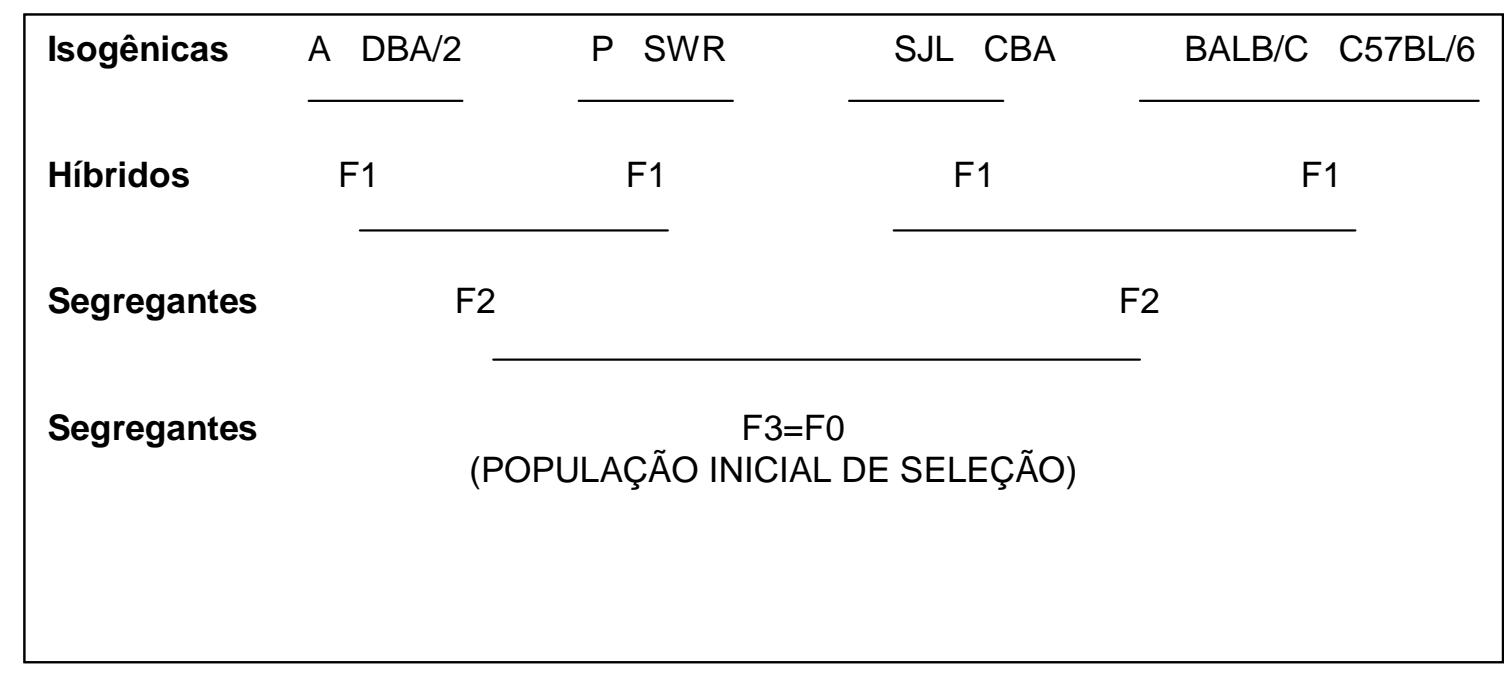

A reação inflamatória aguda (AIR) foi produzida através da injeção subcutânea no dorso dos animais previamente depilados com uma suspensão de microesferas de Biogel P-100 que possuem uma porosidade com limite de exclusão para moléculas acima de 100 Kilodaltons, sendo um polímero quimicamente inerte, não biodegradável e não imunogênico. Os acasalamentos seletivos foram realizados através de cruzamentos baseados no valor fenotípico individual dos dois parâmetros investigados, medidos 24 horas após reação ao Biogel. Estes parâmetros são: quantidade de células infiltradas e concentração protéica no exsudato. $O$ método quantitativo para avaliar a intensidade da reação inflamatória é baseado no modelo proposto por Robert Fauve e colaboradores (FAUVE et al., 1983). As duas características estudadas são positivamente correlacionadas e possuem uma distribuição normal de freqüências o que permite a realização do processo de seleção (RIBEIRO, 1994; IBAÑEZ et al., 1992; STIFFEL et al., 1990). 
Baseando-se na distribuição fenotípica da população F0 foram escolhidos os animais que apresentaram os valores fenotípicos situados nas extremidades da curva, ou seja, para a produção da linhagem de alta reatividade inflamatória aguda (AIRmax), os pais de cada geração foram selecionados entre os camundongos que apresentaram os valores de proteína e celularidade mais altos, enquanto que para a linhagem de baixa reatividade (AIRmin) a escolha foi feita entre os valores mais baixos. Para minimizar a consangüinidade foram evitados os acasalamentos entre irmãos e primos (IBAÑEZ et al., 1992).

A seleção de inflamação atualmente se encontra na $51^{a}$ geração, com uma divergência interlinhagens de 25 vezes para o infiltrado leucocitário e de 2,5 vezes para a concentração de proteína no exsudato. Este caráter é quantitativamente regulado por cerca de 7 a 11 loci gênicos, que segregaram independentemente e que são dotados de efeito aditivo (regulação poligênica) (BIOZZI et al., 1998, IBAÑEZ et al., 1992).
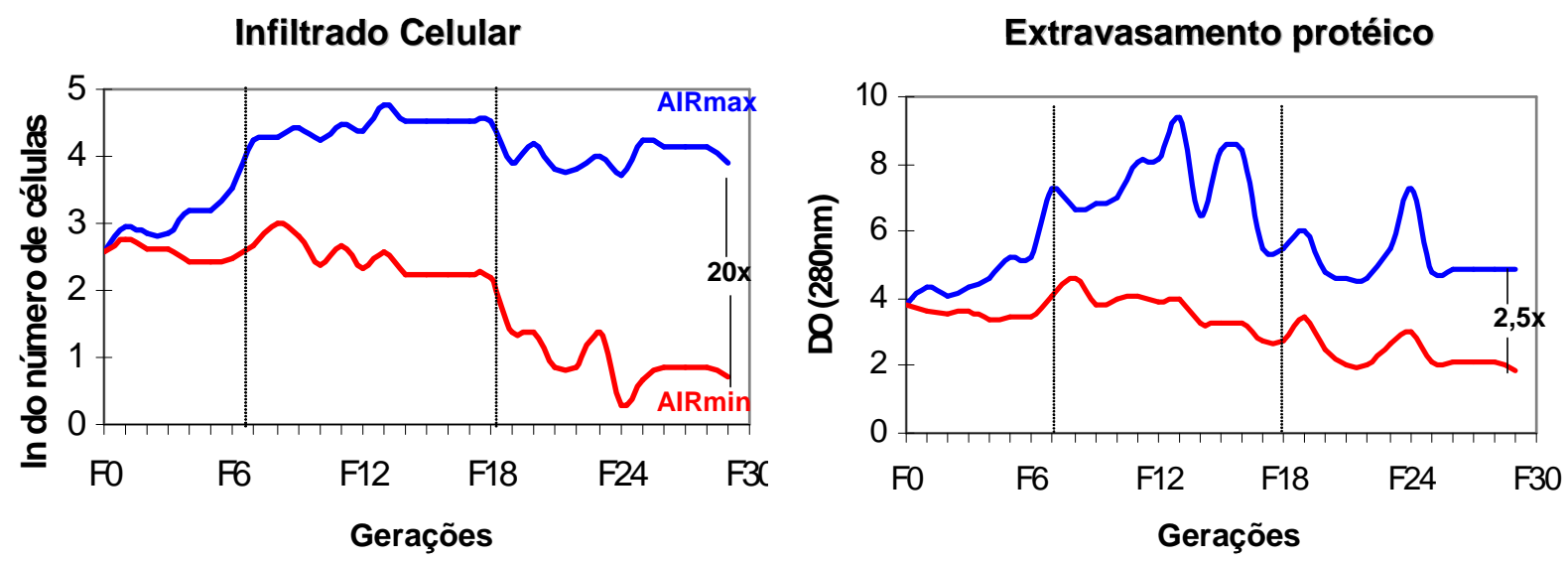

Figura 2: Gráfico representativo da divergência entre as linhagens AIR quanto ao número médio de leucócitos infiltrantes e extravasamento protéico no sítio de injeção do Biogel (Modificado de BIOZZI et al., 1998, com permissão).

Em todas as gerações analisadas de ambas as linhagens, os leucócitos polimorfonucleares constituem o tipo celular predominante no exsudato, às células mononucleares são essencialmente monócitos e 
pequenos linfócitos, estes últimos com contribuição desprezível (RIBEIRO et al., 2003).

Após 20 gerações de acasalamentos seletivos admitiu-se que as linhagens atingiram o máximo de separação fenotípica, chamado de limite de seleção. No limite de seleção os alelos de "boa" resposta para o influxo celular e o exsudato protéico estão em homozigose na linhagem AIRmax, e os alelos de "má" resposta estão em homozigose na linhagem AIRmin (IBAÑEZ et al., 1992).

Além da diferença na capacidade inflamatória aguda, estas linhagens divergem também para a resposta a outros agentes inflamatórios não relacionados entre si ou não relacionados com o Biogel (agente selecionador), como a carragenina (VASQUEZ-BRAVO, 1996), o zimosan e o veneno de Bothrops jararaca (CARNEIRO et al., 2002).

Alterações genéticas decorrentes do processo seletivo interferiram também na resistência e suscetibilidade destas linhagens a doenças tumorais (RIBEIRO et al., 2005; MARIA et al., 2003; BIOZZI et al., 1998), autoimunes (PETERS et al., 2007; VIGAR et al., 2000), e infecciosas (BORREGO et al., 2006; ARAÚJO et al., 1998).

Outro fenótipo que diferencia amplamente as linhagens é a sensibilidade à infecção por Salmonella Typhimurium. Os animais AIRmax são muito resistentes enquanto os animais AIRmin são muito suscetíveis, além disso foi observado um desequilíbrio de freqüência do alelo que confere suscetibilidade $(S)$ do gene "Natural resistanced-associated macrophage protein-1" (Nramp1), estando presente em $60 \%$ nos animais AIRmin e em apenas $9 \%$ nos AIRmax, sugerindo que este desvio tenha ocorrido devido ao processo seletivo, e que o gene Nramp1 ou algum outro gene muito próximo a ele no cromossomo 1 , seria um dos QTL (quantitative trait loci) envolvidos na regulação da intensidade da reação inflamatória aguda (ARAÚjO et al., 1998). Este desequilíbrio de freqüência também interferiu na evolução de artrite induzida pelo pristane (PIA) em animais AIRmax e AIRmin (PETERS et al., 2007). 
Recentemente, o gene Nramp1 foi renomeado como "solute carrier family 11 - proton-coupled divalent metal íon transporter member 1" (Slc11a1) (FORBES et al., 2001).

A proteína codificada pelo gene S/c11a1 localiza-se nos compartimentos endossomal/lisossomal de células fagocitárias, como monócitos/macrófagos e leucócitos polimorfonucleares (CELLIER et al., 1997; VIDAL et al., 1993).

Em camundongos, a expressão do gene S/c11a1 é encontrada no baço, fígado e peritôneo (GOVONI e GROS, 1998) e em humanos, ocorre no pulmão, baço, fígado, e altamente expresso em leucócitos do sangue periférico. Além disso, a expressão do RNAm do gene S/c11a1 pode ser estimulada pelo lipopolissacarídeo de bactérias gram-negativas (LPS) e interferon- $\gamma($ IFN- $\gamma$ ), ou pelo estímulo inflamatório in vivo (CELLIER et al., 1997; GOVONI et al., 1997; VIDAL et al., 1993).

A análise da seqüência da proteína do gene S/c11a1 entre as duas formas alélicas de resistência $(R)$ e de suscetibilidade $(S)$ revelou que uma única mutação, ou seja, uma substituição não conservada do aminoácido glicina por ácido aspártico na posição 169 do códon, dentro do quarto domínio transmembrânico da proteína, resulta na sua completa falta de função, em camundongos suscetíveis (VIDAL et al., 1996). Esta deficiência de funcionalidade causa um acúmulo de íons no interior do fagossomo, favorecendo a replicação de patógenos (HACKAM et al., 1998).

Existe uma homologia entre o gene S/c11a1 murino localizado no cromossomo 1 e o gene SLC11A1 humano localizado no cromossomo 2. Ambos codificam uma proteína de membrana altamente hidrofóbica de aproximadamente $60 \mathrm{kDa}$, com características de uma proteína integral de membrana, que possui 12 domínios transmembrânicos, uma alça extracitoplasmática glicosilada, com vários sítios de fosforilação (BLACKWELL et al., 1995; CELLIER et al., 1995; VIDAL et al., 1993), além de uma seqüência de transporte (Consensus Transport Motif- CTM) estruturalmente homóloga às proteínas de transporte de membrana 
encontradas em bactérias e eucariotos, indicando o envolvimento desta proteína no transporte de íons (Figura 3) (CELLIER et al., 1995).

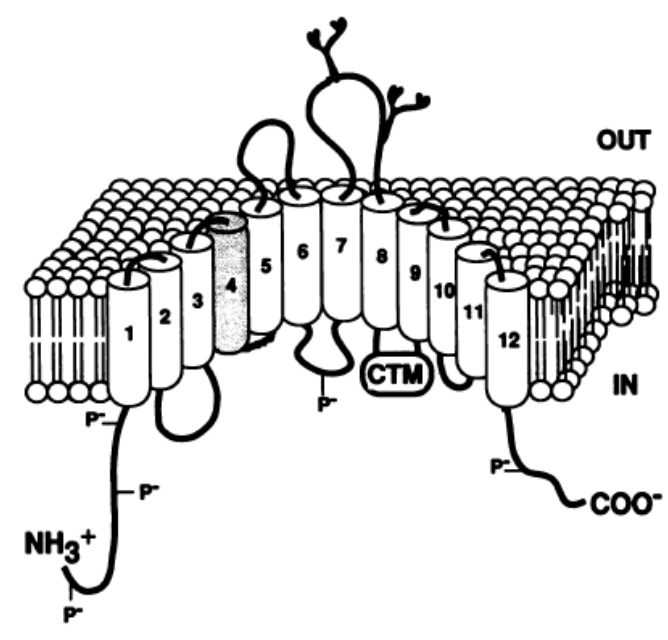

Vidal et al., J Leukoc Biol; 1995.

Figura 3: Figura representativa da proteína de membrana codificada pelo gene S/c11a1.

Quanto à função bioquímica desta proteína existem algumas controvérsias, porém, duas teorias são sugeridas: uma seria que o animal portador do alelo $\mathrm{R}$, ou seja, que codifica a proteína funcional do gene Slc11a1, favoreceria a reação Fenton/Harber-Weiss por meio do transporte de ferro para o interior do fagolisossomo, gerando radicais hidroxilas altamente tóxicos para a bactéria (KUHN et al., 2001), e a segunda teoria propõe que o macrófago do animal que não apresenta a mutação do gene realizaria o transporte de íons eficientemente para fora do fagolisossomo indisponibilizando $\mathrm{Fe}^{+2}$ e cátions divalentes como $\mathrm{Zn}^{+2} \mathrm{e}$ $\mathrm{Mn}^{+2}$ essenciais para o crescimento bacteriano (WYLLIE et al., 2002).

Portanto, o gene Slc11a1 possui efeitos pleiotrópicos e sua expressão defeituosa interfere na ativação macrofágica, refletindo na explosão respiratória, na produção de óxido nítrico (NO) e TNF- $\alpha$ (BARTON et al., 1995). Além disso, interage na produção de IFN- $\gamma$ e IL-1 (RAMARATHINAM et al., 1993; KITA et al., 1992), e na expressão de moléculas do complexo principal de histocompatibilidade (WOJCIECHOWSKI et al., 1999; LANG et al., 1997). 
Com o intuito de estudar a participação do gene S/c11a1 como um possível QTL regulador da intensidade da resposta inflamatória aguda (AIR), o efeito modulador deste gene no desenvolvimento da artrite induzida por pristane (PIA), e a infecção por S. Typhimurium, foram produzidas sublinhagens de camundongos homozigotos para os alelos $\mathrm{R} e$ $S$ deste gene, chamadas de AIRmax ${ }^{R R} ; \operatorname{AIRmax}^{S S} ; \operatorname{AIRmin}^{R R} ; \operatorname{AIRmin}^{S S}$. Estes animais foram obtidos através de cruzamentos assistidos por genotipagem, a partir das linhagens AIRmax e AIRmin da Seleção de Inflamação (PETERS et al., 2007; BORREGO et al., 2006).

Estes animais mantiveram os fenótipos de inflamação e o fundo genético heterogêneo, pois a produção das sublinhagens não afetou a capacidade de máxima e mínima resposta inflamatória aguda dos animais AIRmax e AIRmin, respectivamente. Além disso, as sublinhagens apresentaram o mesmo padrão de polimorfismos identificados nas linhagens parentais AIRmax e AIRmin para microssatélites analisados no cromossomo 1 (PETERS et al., 2007; BORREGO et al., 2006).

Estudos com o objetivo de verificar a relação de loci inflamatórios com o fenótipo de regeneração foram realizados, indicando que a variabilidade deste fenótipo é altamente influenciada pela interação de QTL de inflamação aguda, localizados no cromossomo 1 e 14 . Camundongos da sublinhagem AIRmax ${ }^{S S}$ apresentaram potente regeneração de suas orelhas comparável a linhagem de camundongo isogênico $M R L$, diferente dos animais $A I R m a x{ }^{R R}$ que exibiram regeneração tardia, sugerindo o envolvimento do gene S/c11a1, ou algum outro gene próximo a ele, no controle genético do fenótipo de regeneração, enquanto $\operatorname{AIRmin}^{R R}$ e AIRmin ${ }^{S S}$ apresentaram apenas reparo tecidual parcial da orelha e nenhum indício de regeneração. Animais AIRmax ${ }^{S S}$ fêmeas e AIRmax ${ }^{S S}$ machos também apresentaram diferenças no reparo tecidual (DE FRANCO et al., 2007) (Figura 4). 
Total
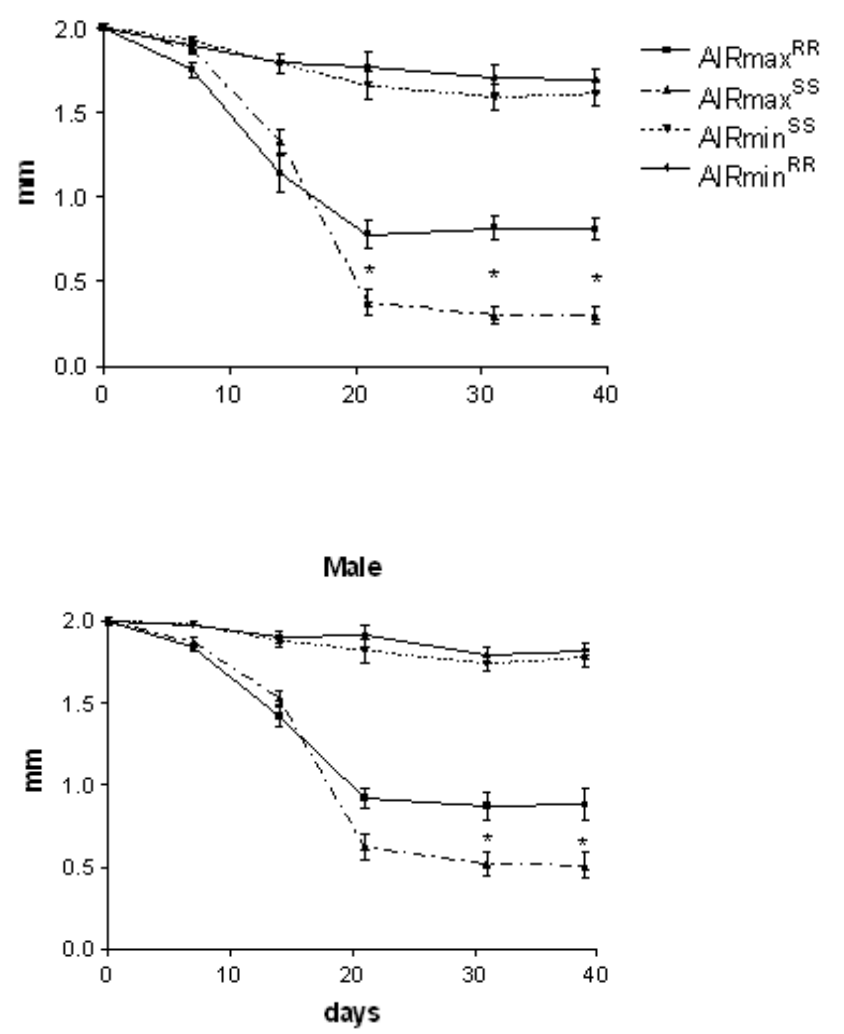

Female

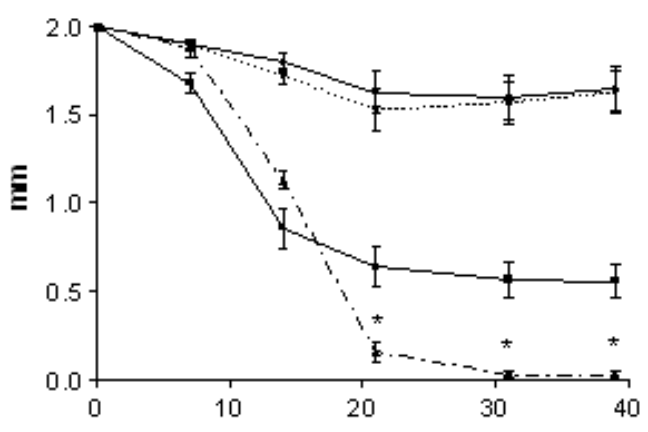

De Franco et al., Mamm Genome; 2007.

Figura 4: Avaliação de regeneração tecidual em diferentes períodos nos camundongos das sublinhagens AIRmax e AIRmin homozigotos para os alelos do gene S/c11a1. Perfurações de $2 \mathrm{~mm}$ foram feitas nas orelhas dos camundongos e 0 fechamento do orifício foi observado durante 40 dias. Os valores estão expressos em média \pm erro padrão. ${ }^{*} p<0,05$.

Portanto, esses dados revelam que a diferença de regeneração à perfuração das orelhas observada em animais $\operatorname{AIRmax}^{R R}$ e AIRmax ${ }^{S S}$ apresentam-se como um modelo experimental muito interessante para o estudo dos mecanismos envolvidos na fase inicial do processo de regeneração tecidual. 


\section{CONCLUSÕES}

- Animais AIRmax ${ }^{S S}$ apresentaram resposta inflamatória local intensa e tardia em resposta à perfuração da orelha em relação aos animais AIRmax ${ }^{R R}$, por meio da formação de edema, pelos níveis de MPO, e pela predominância de neutrófilos na lesão durante a fase inflamatória do processo de regeneração tissular.

- Ensaios de expressão gênica global demonstraram genes diferencialmente expressos entre as sublinhagens, evidenciando genes sobre-representados no tema biológico proliferação celular em ambas sublinhagens, enquanto somente nos animais AIRmax ${ }^{\text {SS }}$ ocorreu sobrerepresentação para resposta inflamatória nos genes ativados e para contração muscular nos genes reprimidos.

- Os resultados obtidos nos experimentos de expressão gênica global foram validados por reações de PCR em tempo real. Uma modulação do alelo $S$ do gene S/c11a1 nos animais AIRmax promoveu uma baixa expressão de genes envolvidos nas primeiras horas da fase inflamatória deste processo, favorecendo desta forma a regeneração do orifício na orelha destes animais. 


\section{REFERÊNCIAS BIBLIOGRÁFICAS ${ }^{1}$}

ACOSTA, J. C.; O'LOGHLEN, A.; BANITO, A.; GUIJARRO, M. V.; AUGERT, A.; RAGUZ, S.; FUMAGALLI, M.; DA COSTA, M.; BROWN, C.; POPOV, N.; TAKATSU, Y.; MELAMED, J.; D'ADDA DI FAGAGNA, F.; BERNARD, D.; HERNANDO, E.; GIL, J. Chemokine signaling via the CXCR2 receptor reinforces senescence. Cell, v. 133, n. 6, p. 1006-1018, 2008.

AMANO, M. T.; CARNEIRO, A. S.; RIBEIRO, O. G.; CABRERA, W. K.; DE FRANCO, M.; IBAÑEZ, O. M.; ISAAC, L.; STAROBINAS, N. A new model of outbred genetically selected mice which present a strong acute inflammatory response in the absence of complement component C5. Inflamm. Res., v. 58, n. 4, p. 204-209, 2009.

ANGELOV, N.; MOUTSOPOULOS, N.; JEONG, M. J.; NARES, S.; ASHCROFT, G.; WAHL, S. M. Aberrant mucosal wound repair in the absence of secretory leukocyte protease inhibitor. Thromb. Haemost., $v$. 92 , n. 2, p. 288-297, 2004.

ANTRUM, R. M.; SOLOMKIN, J. S. Monocyte dysfunction in severe trauma: evidence for the role of $\mathrm{C} 5 \mathrm{a}$ in deactivation. Surgery, v. 100, n. 1, p. 29$37,1986$.

ARAUJO, L. M. M.; RIBEIRO,O. G.; SIQUEIRA, M.; DE FRANCO, M.; STAROBINAS, N.; MASSA, S.; CABRERA, W. H. ; MOUTON, D.; SEMAN, M. ; IBAÑEZ, O. M. Innate Resistence to Infections by Intracellular Bacteria Differs in Mice Selected for Maximal or Minimal Acute Inflammatory Response. Eur. J. Immunol., v. 28, n. 9, p. 2913- 2920, 1998.

ASAGOE, K.; YAMAMOTO, K.; TAKAHASHI, A.; SUZUKI, K.; MAEDA, A.; NOHGAWA, M.; HARAKAWA, N.; TAKANO, K.; MUKAIDA, N.; MATSUSHIMA, K.; OKUMA, M.; SASADA, M. Down-regulation of CXCR2 expression on human polymorphonuclear leukocytes by TNF-alpha. J. Immunol., v. 160, n. 9, p. 4518-4525, 1998.

BARTON, C. H.; WHITEHEAD, S. H.; BLACKWELL, J. M. Nramp Transfection Transfers Ity/Lsh/Bcg- Related Pleiotropic Effects on Macrophage Activation: Influence on Oxidative Burst and Nitric Oxide Pathways. Mol. Med., v. 1, p. 267- 279, 1995.

\footnotetext{
1 *De acordo com: ASSOCIAÇÃO BRASILEIRA DE NORMAS TÉCNICAS. NBR 6023: Informação e documentação: referências: elaboração. Rio de Janeiro, 2002.
} 
BEN MOSHE, T.; BARASH, H.; KANG, TB.; KIM, JC.; KOVALENKO, A.; GROSS, E.; SCHUCHMANN, M.; ABRAMOVITCH, R.; GALUN, E.; WALLACH, $D$. Role of caspase-8 in hepatocyte response to infection and injury in mice. Hepatology, v. 45, n. 4, p. 1014-24, 2007.

BIOZZI, G.; RIBEIRO, O. G.; SARAN, A.; ARAUJO, M. L. ; MARIA, D. A.; DE FRANCO, M.; CABRERA, W. K.; SANT'ANNA, O.A.; MASSA, S.; COVELLI, V.; MOUTON, D.; NEVEU, T.; SIQUEIRA, M.; IBANEZ, O. M. Effect of Genetic Modification of Acute Inflammatory Responsiveness on Tumorigenesis in the Mouse. Carcinogenesis, v. 19, p. 337-346, 1998.

BJARNSHOLT, T.; KIRKETERP-MØLLER, K.; JENSEN, PØ.; MADSEN, KG.; PHIPPS, R.; KROFELT, K.; HØIBY, N.; GIVSKOV, M. Why chronic wounds will not heal: a novel hypothesis. Wound Repair Regen., v. 16, n. 1, p. 2-10, 2008.

BLACKWELL, J. M.; BARTON, C. H.; WHITE, J. K.; SEARLE, S.; BAKER, A. M.; WILLIAMS, H.; et al. Genomic Organization and Sequence of the Human NRAMP1 Gene: Identification and Mapping of a Promoter Region Polymorphism. Mol. Med., v. 1, p. 194- 205, 1995.

BLANKENHORN, E. P.; TROUTMAN, S.; CLARK, L. D.; ZHANG, X.; CHEN, P.; HEBER- KATZ, E. Sexually Dimorphic Genes Regulate Healing and Regeneration in MRL Mice. Mamm. Genome, v. 14, p. 250- 260, 2003.

BLEHARSKI, J. R.; KIESSLER, V.; BUONSANTI, C.; SIELING, PA.; STENGER, S.; COLONNA, M.; MODLIN, R. L. A role for triggering receptor expressed on myeloid cells- 1 in host defense during the early-induced and adaptive phases of the immune response. J. Immunol., v. 170, n. 7, p. 3812-3818, 2003.

BORDER, W. A.; NOBLE, N. A. Transforming growth factor beta in tissue fibrosis. N. Engl. J. Med., v. 331, p. 1286-92, 1994.

BORREGO, A.; PETERS, L. C.; JENSEN, J. R.; RIBEIRO, O. G.; CABRERA, W. H. K.; STAROBINAS, N.; SEMAN, M.; IBAÑEZ, O. M.; DE FRANCO, M. Genetic Determinants of Acute Inflammation Regulate Salmonella Infection and Modulate S/c11a1Gene (Formerly Nramp1) Effects in Selected Mouse Lines. Microbes Infect., v. 8, p. 2766- 2771, 2006.

BOUCHON, A.; DIETRICH, J.; COLONNA, M. Cutting edge: inflammatory responses can be triggered by TREM-1, a novel receptor expressed on neutrophils and monocytes. J. Immunol., v. 164, n. 10, p. 4991-4995, 2000. 
BOUCHON, A.; HERNÁNDEZ-MUNAIN, C.; CELLA, M.; COLONNA, M. A DAP12-mediated pathway regulates expression of CC chemokine receptor 7 and maturation of human dendritic cells. J. Exp. Med., v. 194, n. 8, p. 1111-1122, 2001.

BOUKHALFA, G.; DESMOULIÈRE, A.; RONDEAU, E.; GABBIANI, G.; SRAER, J. D. Relationship between alpha-smooth muscle actin expression and fibrotic changes in human kidney. Exp. Nephrol., v. 4, n. 4, p. 241247, 1996.

CARNEIRO, A. S.; RIBEIRO, O. G.; DE FRANCO, M.; CABRERA, W. H.; VORRARO, F.; SIQUEIRA, M.; IBAÑEZ, O. M.; STAROBINAS, N. Local inflammatory reaction induced by Bothrops jararaca venom differs in mice selected for acute inflammatory response. Toxicon, v. 40, p. 1571-1579, 2002.

CARNEIRO, P. S.; PETERS, L. C.; VORRARO, F.; BORREGO, A.; RIBEIRO, O. G.; STAROBINAS, N.; JENSEN, J. R.; CABRERA, W. H. K.; IBAÑEZ, O. M.; DE FRANCO, M. Gene expression profiles of bone marrow cells from mice phenotype-selected for maximal or minimal acute inflammations: searching for genes in acute Inflammation modifier loci. Immunology, v. 128, p. 562-571, 2009.

CELLIER, M.; PRIVE, G.; BELOUCH, A.; KWAN, T.; RODRIGUES, V.; CHIA, W.; GROS, P. Nramp Defines a Family of Membrane Proteins. Proc. Natl. Acad. Sci. USA, v. 92, p. 10089- 10093, 1995.

CELLIER, M.; SHUSTIK, C.; DALTON, W.; RICH, E.; HU, J.; MALO, D.; et al. The Human NRAMP1 Gene as a Marker of Professional Primary Phagocytes: Studies in Blood Cells and in Induced HL- 60 Promyelocytic Leukemia. J. Leuk. Biol., v. 61, p. 96- 105, 1997.

CLARK, L. D; CLARK, R. K; HEBER-KATZ, E. A new murine model for mammalian wound repair and regeneration. Clin. Immunol. Immunopathol., v. 88, n. 1, p. 35-45, 1998.

COLONNA, M. DAP12 signaling: from immune cells to bone modeling and brain myelination. J. Clin. Invest., v. 111, n. 3, p. 313-314, 2003.

COLONNA, M. TREMs in the immune system and beyond. Nat. Rev. Immunol., v. 3, n. 6, p. 445-453, 2003.

DANON, D.; KOWATCH, M. A.; ROTH, G. S. Promotion of Wound Repair in Old Mice by Local Injection of Macrophages. Proc. Natl. Acad. Sci. USA, v. 86, p. 2018-2020, 1989. 
DE BENTZMANN. S.; POLETTE, M.; ZAHM, J. M.; HINNRASKY, J.; KILEZTKY, C.; BAJOLET, O.; KLOSSEK, J. M.; FILLOUX, A.; LAZDUNSKI, A.; PUCHELLE E. Pseudomonas aeruginosa virulence factors delay airway epithelial wound repair by altering the actin cytoskeleton and inducing overactivation of epithelial matrix metalloproteinase-2. Lab. Invest., v. 80 , p. 209-219, 2000.

DE FRANCO, M.; CARNEIRO, P. S.; PETERS, L. C.; VORRARO, F.; BORREGO, A.; RIBEIRO, O.G.; STAROBINAS, N.; CABRERA, W. K.; IBAÑEZ, O. M. Slc11a1 (Nramp1) Alleles Interact with Acute Inflammation Loci to Modulate Wound Healing Traits in Mice. Mamm. Genome, v. 18, n. 4, p. 263-269, 2007.

DEVALARAJA, R. M.; NANNEY, L. B.; DU, J.; QIAN, Q.; YU, Y.; DEVALARAJA, M. N.; RICHMOND, A. Delayed wound healing in CXCR2 knockout mice. J. Invest. Dermatol., v. 115, n. 5, p. 931, 2000.

DOVI, J. V.; HE, L. K.; DIPIETRO, L. A. Accelerated wound closure in neutrophil-depleted mice. J. Leukoc. Biol., v. 73, n. 4, p. 448-455, 2003.

DOVI, J. V.; SZPADERSKA, A. M.; DIPIETRO, L. A. Neutrophil Function in the Healing Wound: Adding Insult to Injury? Thromb. Haemost., v. 92, n. 2, p. 275-280, 2004. Review.

EMING, S. A.; WERNER, S.; BUGNON, P.; WICKENHAUSER, C.; SIEWE, L. ; UTERMOHLEN, O.; DAVIDSON, J. M.; KRIEG, T.; ROERS, A. Accelerated Wound Closure in Mice Deficient for Interleukin-10. Am. J. Pathol., v. 170, n. 1, p. 188- 202, 2007.

FAUVE, R. M.; JUSFORGUES, H.; HEVIN, B. Maintenance of Granuloma Macrophages in Serum-Free Medium. J. Immunol. Methods, v. 64, p. 345, 1983.

FERGUSON, K. L. ; TAHERI, P.; RODRIGUEZ, J.; TONAPI, V.; CARDELLIO, A.; DECHERT, R. Tumor necrosis factor activity increases in the early response to trauma. Acad. Emerg. Med., v. 4, p. 1035-1040, 1997.

FORBES, J. R.; GROS, P. Divalent- metal Transport by NRAMP Proteins at the Interface of Host- Pathogen Interactions. Trends Microbiol., v. 9, p. 397- 403, 2001.

GABAY, C. Interleukin-6 and chronic inflammation. Arthritis Res. Ther., v. 8, p. 1-6, 2006. Suppl. 2:S3. 
GERARD, C.; GERARD, N. P. C5A anaphylatoxin and its seven transmembrane-segment receptor. Annu. Rev. Immunol., v. 12, p. 775-808, 1994.

GIBOT, S.; MASSIN, F.; MARCOU, M.; TAYLOR, V.; STIDWILL, R.; WILSON, P.; SINGER, M.; BELLINGAN, G. TREM-1 promotes survival during septic shock in mice. Eur. J. Immunol., v. 37, p. 456-466, 2007.

GILLITZER, R.; GOEBELER, M. Chemokines in cutaneous wound healing. J. Leukoc. Biol., v. 69, n. 4, p. 513-521, 2001. Review.

GIULIETTI， A.; OVERBERGH， L.; VALCKX， D.; DECALLONNE， B.; BOUILLON, R.; MATHIEU, C. An overview of Real-Time quantitative PCR Applications to quantify cytokine gene expression. Methods, v. 25, p. 386-401, 2001.

GOVONI, G.; GAUTHIER, S.; ISCOVE, N. N.; GROS, P. Cell Specific and Inducible Nramp1 Gene Expression in Macrophages in vitro and in vivo. J. Leukoc. Biol., v. 62, p. 277-286, 1997.

GOVONI, G.; GROS, P. Macrophage NRAMP1 and its Role in Resistance to Microbial Infections. Inflamm. Res., v. 47, p. 277- 284, 1998.

GOUREVITCH, D.; CLARK, L.; CHEN, P.; SEITZ, A.; SAMULEWICZ, S. J.; HEBER-KATZ, E. Matrix metalloproteinase activity correlates with blastema formation in the regenerating MRL mouse ear hole model. Dev. Dyn., v. 226, n. 2, p. 377-387, 2003.

GUERNE, P. A.; DESGEORGES, A.; JASPAR, J. M.; RELIC, B.; PETER, R.; HOFFMEYER, P.; DAYER, J. M. Effects of IL- 6 and its soluble receptor on proteoglycan synthesis and NO release by human articular chondrocytes: comparison with IL-1. Modulation by dexamethasone. Matrix Biol., v. 18, n. 3, p. 253-260, 1999.

GUO, R. F.; WARD, P. A. Role of C5a in inflammatory responses. Annu. Rev. Immunol., v. 23, p. 821-852, 2005.

GURTNER, G. C.; WERNER, S.; BARRANDON, Y.; LONGAKER, M. T. Wound repair and regeneration. Nature, v. 453, p. 314-321, 2008. Review.

HACKAM, D. J.; ROTSTEIN, O. D.; ZHANG, W.; GRUENHEID, S.; GROS, P.; GRINSTEIN, S. Host Resistance to Intracellular Infection: Mutation of Natural Resistance- Associated Macrophage Protein 1 (Nramp1) Impairs Phagosomal Acidification. J. Exp. Med., v. 188, p. 351- 364, 1998. 
HAMERMAN, J. A.; JARJOURA, J. R.; HUMPHREY, M. B.; NAKAMURA, M. C.; SEAMAN, W. E.; LANIER, L. L. Cutting edge: inhibition of TLR and FCR responses in macrophages by triggering receptor expressed on myeloid cells (TREM)-2 and DAP12. J. Immunol., v. 177, n. 4, p. 2051-2055, 2006.

HEBER-KATZ, E. The regenerating mouse ear. Semin. Cell Develop. Biol., v. 10, p. 415-419, 1999.

HOSACK, D. A.; DENNIS, G. JR.; SHERMAN, B. T.; LANE, H. C.; LEMPICK, R. A. Identifying biological themes within lists of genes with EASE. Genome Biol., v. 4, n. 10, r. 70, 2003.

HÜBNER, G.; BRAUCHLE, M.; SMOLA, H.; MADLENER, M.; FÄSSLER, R.; WERNER, $S$. Differential regulation of pro-inflammatory cytokines during wound healing in normal and glucocorticoid-treated mice. Cytokine, v. 8, p. 548-556, 1996.

IBAÑEZ, O. M.; STIFFEL, C.; RIBEIRO, O. G.; CABRERA, W. K.; MASSA, S.; DE FRANCO, M.; et al. Genetics of Nonspecific Immunity: I. Bidirectional Selective Breeding of Lines of Mice Endowed with Maximal or Minimal inflammatory Responsiveness. Eur. J. Immunol., v. 22, p. 25552563, 1992.

IKEMA, K.; MATSUMOTO, K.; INOMATA, Y.; KOMOHARA, Y.; MIYAJIMA, S.; TAKEYA, M.; TANIHARA, $H$. Induction of matrix metalloproteinases (MMPs) and tissue inhibitors of MMPs correlates with outcome of acute experimental pseudomonal keratitis. Exp. Eye Res., v. 83, p. 1396-404, 2006.

ISHIDA, Y.; KONDO, T.; KIMURA, A.; MATSUSHIMA, K.; MUKAIDA, N. Absence of IL-1 receptor antagonist impaired wound healing along with aberrant NF-kappaB activation and a reciprocal suppression of TGF-beta signal pathway. J. Immunol., v. 176, p. 5598-5606, 2006.

ISHIHARA, K.; HIRANO, T. IL-6 in autoimmune disease and chronic inflammatory proliferative disease. Cytokine Growth Factor, v. 13, p. 357-68, 2002. Review.

JOHNSTON, R. A.; MIZGERD, J. P.; SHORE, S. A. CXCR2 is essential for maximal neutrophil recruitment and methacholine responsiveness after ozone exposure. Am. J. Physiol. Lung Cell Mol. Physiol., v. 288, n. 1, p. $61-67,2005$. 
KITA, E.; EMOTO, M.; OKU, D.; NISHIKAWA, F.; HAMURU, A.; KAMIKAIDOU, N.; KASHIBA, S. Contribution of Interferon Gamma and Membrane- Associated Interleukin 1 to the Resistance to Murine Typhoid of Ity r Mice. J. Leukoc. Biol., v. 51, p. 244- 250, 1992.

KLESNEY-TAIT, J.; TURNBULL, I. R.; COLONNA, M. The TREM receptor family and signal integration. Nat. Immunol., v. 7, p. 1266-1273, 2006.

KRUIDERING, M.; EVAN, G. I. Caspase- 8 in apoptosis: the beginning of "the end"? IUBMB Life, v. 50, n. 2, p. 85-90, 2000.

KUHN, D. E.; LAFUSE, W. P.; ZWILLING, B. S. Iron transport into mycobacterium avium-containing phagosomes from an Nramp1(Gly 169)transfected RAW264.7 macrophage cell line. J. Leukoc. Biol., v.69, p. 43-49, 2001.

LANG, T.; PRINA, E.; SIBTHORPE, D.; BLACKWELL, J. M. Nramp1 Transfection Transfer Ity/Lsh/Bcg - Related Pleiotropic Effects on Macrophage Activation: Influence on Antigen Processing and Presentation. Infect. Immun., v. 65, p. 380- 386, 1997.

LANIER, L. L.; BAKKER, A. B. The ITAM bearing transmembrane adaptor DAP12 in lymphoid and myeloid cell function. Immunol. Today, v. 21, p. 611-614, 2000.

LEASK, A.; ABRAHAM, D. J. TGF-beta signaling and the fibrotic response. FASEB J., v. 18, n. 7, p. 816-27, 2004.

LEIBOVICH, S. J.; ROSS, R. The Role of the Macrophage in Wound Repair. Astudy with Hydrocortisone and Antimacrophage Serum. Am. J. Pathol., v. 78, p. 71-100, 1975.

LI, X.; GU, W.; MASINDE, G.; HAMILTON-ULLAND, M.; XU, S.; MOHAN, S.; BAYLINK, D. J. Genetic Control of the Rate of Wound Healing in Mice. Heredity, v. 86, p. 668-674, 2001.

LIAN, X.; YANG, L.; GAO, Q .; YANG, T. IL-1alpha is a potent stimulator of keratinocyte tissue plasminogen activator expression and regulated by TGF-beta1. Arch. Dermatol. Res., v. 300, n. 4, p. 185-193, 2008.

LIN, E.; CALVANO, S. E.; LOWRY, S. F. Inflammatory cytokines and cell response in surgery. Surgery, v. 127, n. 2, p. 117-126, 2000. Review.

LINARES, H. A. From wound to scar. Burns, v. 22, p. 339-52, 1996. 
LIVAK, K. J.; SCHMITTGEN, T. D. Analysis of relative gene expression data using Real-Time quantitative PCR and the $2^{-\Delta \Delta C_{t}}$ method. Methods, v. 25, p. 402-408, 2001.

LOBMANN, R.; SCHULTZ, G.; LEHNERT, H. Proteases and the diabetic foot syndrome: mechanisms and therapeutic implications. Diabetes Care, v. 28, p. 461-471, 2005.

MARIA, D. A.; MANETTI, G.; GALBIATI, F.; RIBEIRO, O. G.; DE FRANCO, M.; STAROBINAS, N.; SIQUEIRA, M.; DRAGANI, T. A.; IBAÑEZ, O. M. Pulmonary Adenoma Susceptibility 1 (Pas1) locus Affects Inflammatory Response. Oncogene, v. 22, p. 426-432, 2003.

MARTIN, P. Wound Healing-Aiming for Perfect Skin Regeneration. Science, v. 276, n. 5309, p. 75-81, 1997.

MASINDE, G. L.; LI, X.; GU, W.; DAVIDSON, H.; MOHAN, S.; BAYLINK, D. J. Identification of Wound Healing/Regeneration Quantitative Trait Loci (QTL) at Multiple Time Points that Explain Seventy Percent of Variance in (MRL/Mpj And SJL/J) Mice F2 Population. Genome Res., v. 12, p. 20272033, 2001.

MASSAGUe, J. TGF-beta signal transduction. Annu. Rev. Biochem., v. 67, p. 753-791, 1998.

MASTELLOS, D. The ITAM bearing transmembrane adaptor DAP12 in lymphoid and myeloid cell function.; PAPADIMITRIOU, J. C.; FRANCHINI, S.; TSONIS, P. A.; LAMBRIS, J. D. A novel role of complement: mice deficient in the fifth component of complement (C5) exhibit impaired liver regeneration. J. Immunol., v. 166, p. 2479-2486, 2001.

MCBREARTY,B. A.; CLARK, L. D.; ZHANG, X. M.; BLANKENHORN, E. P.; HEBER-KATZ, E. Genetic Analysis of a Mammalian Wound-Healing Trait. Genetics, v. 95, p. 11792-11797, 1998.

MCCARTNEY-FRANCIS, N. L.; FRAZIER-JESSEN, M.; WAHL, S. M. TGFbeta: a balancing act. Int. Rev. Immunol., v. 16, p. 553-580, 1998.

MCCOURT, M.; WANG, J. H.; SOOKHAI, S.; REDMOND, H. P. Proinflammatory Mediators Stimulate Neutrophil-Directed Angiogenesis. Arch. Surg., v. 134, p. 1325-31; discussion 1331-2, 1999.

MONACO, J. L.; LAWRENCE, W. T. Acute wound healing an overview. Clin. Plast. Surg., v. 30, n. 1, p. 1-12, 2003. 
MUKHERJEE, T. K.; DINH, H.; CHAUDHURI, G.; NATHAN, L. Testosterone Attenuates Expression of Vascular Cell Adhesion Molecule-1 by Conversion to Estradiol by Aromatase in Endothelial Cells: Implications in Atherosclerosis. Proc. Natl. Acad. Sci. USA, v. 99, p. 4055- 4060, 2002.

MURATA, H.; ZHOU, L.; OCHOA, S.; HASAN, A.; BADIAVAS, E.; FALANGA, $V$. TGF-beta3 stimulates and regulates collagen synthesis through TGF-beta1-dependent and independent mechanisms. J. Invest. Dermatol., v. 108, p. 258-62, 1997.

MURPHY, P. M. Neutrophil receptors for interleukin-8 and related CXC chemokines. Semin. Hematol., v. 3, p. 311-318, 1997.

O'DWYER, M. J.; MANKAN, A. K.; STORDEUR, P.; O'CONNELL, B.; DUGGAN, E.; WHITE, M.; KELLEHER, D. P.; MCMANUS, R.; RYAN, T. The occurrence of severe sepsis and septic shock are related to distinct patterns of cytokine gene expression. Shock, v. 26, n. 6, p. 544-550, 2006.

OPALENIK, S. R.; DAVIDSON, J. M. Fibroblast differentiation of bone marrow-derived cells during wound repair. FASEB J., v. 19, p. 15611563, 2005.

OWEN, C. A.; HU, Z.; BARRICK, B.; SHAPIRO, S. D. Inducible Expression of Tissue Inhibitor of Metalloproteinases-Resistant Matrix Metalloproteinase- 9 on the Cell Surface of Neutrophils. Am. J. Respir. Cell Mol. Biol., v. 29, p. 283-294, 2003.

PARKS, W. C.; WILSON, C. L.; LÓPEZ-BOADO, Y. S. Matrix metalloproteinases as modulators of inflammation and innate immunity. Nat. Rev. Immunol., v. 4, n. 8, p. 617-629, 2004.

PETERS, L. C.; JENSEN, J. R.; BORREGO, A.; CABRERA, W. H .K.; BAKER, N.; STAROBINAS, N.; RIBEIRO, O. G.; IBAÑEZ, O. M.; DE FRANCO, M. Slc11a1 (Formerly NRAMP1) Gene Modulates both Acute Inflammatory Reactions and Pristane-Induced Arthritis in Mice. Genes Immun., v. 8, p. 51- 56, 2007.

PLOWDEN, J.; RENSHAW-HOEISCHER, M.; ENGLEMAN, C.; KATZ, J.; SAMBHARA, $S$. Innate Immunity in Aging: Impact on Macrophage Function. Aging Cell, v. 3, n. 4, p. 161-7, 2004. Review.

RAJNOCH, C.; FERGUSON, S.; METCALFE, A. D.; HERRICK, S. E.; WILLIS, H. S.; FERGUSON, M. W. Regeneration of the ear after wounding in different mouse strains is dependent on the severity of wound trauma. Dev. Dyn., v. 226, n. 2, p. 388-397, 2003. 
RAMARATHINAM, L.; NIESEL, D. W.; KIMPEL, G. R. Ity Influences the Production of IFN- gamma by Murine Splenocytes Stimulated in vitro with Salmonella typhimurium. J. Immunol., v. 150, p. 3965- 3972, 1993.

RAKOFF-NAHOUM, S.; MEDZHITOV, R. Toll-like receptors and cancer. Nat. Rev. Cancer, v. 9, n. 1, p. 57-63, 2009. Review.

REINES, B.; CHENG, L.; MATZINGER, P. Unexpected regeneration in middle aged mice. Rejuvenation Res., v. 12, n. 1, p. 45-52, 2009.

RENNEKAMPFF, H. O.; HANSBROUGH, J. F.; KIESSIG, V.; et al. Bioactive Interleukin-8 is Expressed in Wounds and Enhances Wound Healing. $J$. Surg. Res., v. 93, p. 41- 54, 2000.

RIBEIRO, O.G. Controle Genético da Inflamação. Tese (Mestrado) Escola Paulista de Medicina, São Paulo, 1994.

RIBEIRO, O. G. ; MARIA, D. A. ; ADRIOUCH, S. ; PECHBERTY, S. ; CABRERA, W. H. K. ; MORISSET, J.; IBAÑEZ, O. M.; SEMAN, M. Convergent Alteration of Granulopoieses, Chemotactic Activity, and Neutrophil Apoptosis During Mouse Selection for High Acute Inflammatory Response. J. Leukoc. Biol., v. 74, p. 497-506, 2003.

RIBEIRO, O. G.; CABRERA, W. H.; MARIA, D. A.; DE FRANCO, M.; MASSA, S.; DI PACE, R. F.; DE SOUZA, V. R.; STAROBINAS, N.; SEMEN, M.; IBAÑEZ, O. M. Genetic Selection for High Acute Inflammatory Response Confers Resistence to Lung Carcinogenesis in the Mouse. Lung Res., v. 31 , p. 105-116, 2005.

ROBERTSON, F. M.; PELLEGRINI, A. E.; ROSS, M. S.; OBERYSZYN, A. S.; BOROS, L. G.; BIJUR, G. N.; SABOURIN, C. L.; OBERYSZYN, T. M. Interleukin-1alpha gene expression during wound healing. Wound Repair Regen., v. 3, p. 473-484, 1995.

ROTHE, M.; FALANGA, V. Growth factors and wound healing. Clin. Dermatol., v. 9, p. 553-559, 1992.

SAKLATVALA, J. Inflammatory signaling in cartilage: MAPK and NF-kappa pathways in chondrocytes and the use of inhibitors for research into pathogenesis and therapy of osteoarthritis. Curr. Drug Targets, v. 8, n. 2, p. 305-313, 2007.

SATO, Y.; OHSHIMA, T. The expression of mRNA of proinflammatory cytokines during skin wound healing in mice: a preliminary study for forensic wound age estimation (II). Int. J. Legal Med., v. 113, p. 140145, 2000. 
SCHÄFFER, M.; BONGARTZ, M.; HOFFMANN, W.; VIEBAHN, R. MHC-ClassII-Deficiency Impairs Wound Healing. J. Surg. Res., v. XX, p. 1- 6, 2006.

SCHÄFER, M.; WERNER, S. Cancer as an overhealing wound: an old hypothesis revisited. Nat. Rev. Mol. Cell Biol., v. 9, n. 8, p. 628-638, 2008. Review.

SCHROEDER, $T$. Imaging stem-cell-driven regeneration in mammals. Nature, v. 453, p. 345-351, 2008. Review.

SHI, Y.; PESTKA, J. J. Mechanisms for suppression of interleukin-6 expression in peritoneal macrophages from docosahexaenoic acid-fed mice. J. Nutr. Biochem., v. 20, n. 5, p. 358-368, 2009.

SINGER, A. J.; CLARK, R. A. F. Cutaneous Wound Healing. N. Engl. J. Med., v. 341, n. 10, p. 738-746, 1999.

STIFFEL, C.; IBAÑEZ, O.M.; RIBEIRO, O.G.; DECREUSEFOUND,C.; MOUTON,D.; SIQUEIRA, M.; BIOZZI, G. Genetic of Acute Inflammation: Inflammatory Reactions in Inbred Lines of Mice and in Their Interline Crosses. Exp. Clin. Immunogenetics, v. 7, p. 221-233, 1990.

STOCUM, D. L. Tissue restoration: approaches and prospects. Wound Repair Regen., v. 4, n. 1, p. 3-15, 1996.

STRIETER, R. M.; POLVERINI, P. J.; KUNKEL, S. L.; ARENBERG, D. A.; BURDICK, M. D.; KASPER, J.; DZUIBA, J.; VAN DAMME, J.; WALZ, A.; MARRIOTT, D.; et al. The functional role of the ELR motif in CXC chemokine-mediated angiogenesis. J. Biol. Chem., v.270, n. 45, p. 27348-27357, 1995.

SUE, R. D.; BELPERIO, J. A.; BURDICK, M. D.; MURRAY, L. A. ; XUE, Y. Y.; DY, M. C.; KWON, J. J.; KEANE, M. P.; STRIETER, R. M. CXCR2 is critical to hyperoxiainduced lung injury. J. Immunol., v. 172, p. 3860-3868, 2004.

TOMASELLO, E.; OLCESE, L.; VÉLY, F.; GEOURGEON, C.; BLÉRY, M.; MOQRICH, A.; GAUTHERET, D.; DJABALI, M.; MATTEI, M. G.; VIVIER, E. Gene structure, expression pattern, and biological activity of mouse killer cell activating receptor-associated protein (KARAP)/DAP-12. J. Biol. Chem., v. 273, p. 34115-34119, 1998.

TSAI, W. C.; STRIETER, R. M.; MEHRAD, B.; NEWSTEAD, M. W.; ZENG, $X . ;$ STANDIFORD, T. J. CXC chemokine receptor CXCR2 is essential for protective innate host response in murine Pseudomonas aeruginosa pneumonia. Infect. Immun., v. 68, p. 4289-4296, 2000. 
TSIROGIANNI, A. K.; MOUTSOPOULOS, N. M.; MOUTSOPOULOS, H. M. Wound healing: immunological aspects. Injury, v. 37S, p. S5-S12, 2006.

TURNBULL, I. R.; GILFILLAN, S.; CELLA, M.; AOSHI, T.; MILLER, M.; PICCIO, L.; HERNANDEZ, M.; COLONNA, M. Cutting edge: TREM-2 attenuates macrophage activation. J. Immunol., v. 177, p. 3520-3524, 2006.

VAN BERGE HENEGOUWEN, M. I.; VAN DER POLL, T.; VAN DEVENTER, S. J. H.; GOUMA, D. J. Peritoneal cytokine release after elective gastrointestinal surgery and postoperative complications. Am. J. Surg., v. 175 , p. 311-316, 1998. Review.

VAN DER POLL.; LOWRY, S. F. Tumor necrosis factor in sepsis: Mediator of multiple organ failure or essential part of host defense? Shock, v. 3, p. 112, 1995. Review.

VASQUEZ- BRAVO, Y. L. A. R. Aspecto da Resposta Inflamatória Aguda em Linhagens de Camundongos com Reatividade Máxima (AIRmax) e Mínima (AIRmin) Obtidas por Seleção Genética Bidirecional. Tese (Doutorado) - Universidade de São Paulo, São Paulo, 1996.

VIDAL, S. M.; MALO, D.; VOGAN, K.; SKAMENE, E.; GROS, P. Natural Resistance to Infection with Intracellular Parasites: Isolation of a Candidate for Bcg. Cell, v. 73, p. 469- 485, 1993.

VIDAL, S. M.; PINNER, E.; GAUTHIER, S.; LEPAGE, P.; GROS, P. Nramp1 is na Integral Membrane Phosphoglycoprotein Absent from Macrophages of Inbred Mouse Strains Susceptible to Infection with Intracellular Parasites. J. Immunol., v. 157, p. 3559- 3568, 1996.

VIDAL, S. M.; PINNER, E.; LEPAGE, P.; GAUTHIER, S.; GROS, P. Natural Resistence to Intracellular Infections: Nramp1 Encodes a Membrane Phosphoglycoprotein Absent in Macrophages from Susceptible (Nramp1 D169) mouse Strains. J. Immunol., v. 157, p. 3559- 3568, 1996.

VIGAR, N. D.; CABRERA, W. K.; ARAUJO, L. M. M.; RIBEIRO, O. G.; OGATA, T. R. P.; SIQUEIRA, M.; et al. Pristane- induced Arthritis in Mice Selected for Maximal or Minimal Acute Inflamatory Reaction. Eur. J. Immunol., v. 30, p. 431-437, 2000.

WALPORT, M. J. Complement. Second of two parts. N. Engl. J. Med., v. 344, p. 1140-1144, 2001. 
WATFORD, W. T.; MORIGUCHI, M.; MORINOBU, A.; O'SHEA, J. J. The biology of IL-12: coordinating innate and adaptive immune responses. Cytokine Growth Factor, v. 14, n. 5, p. 361-368, 2003. Review.

WELLER, K.; FOITZIK, K.; PAUS, R.; SYSKA, W.; MAURER, M. Mast cells are required for normal healing of skin wounds in mice. FASEB J., v. 20, n. 13, p. 2366-2368, 2006.

WERNER, S.; GROSE, R. Regulation of wound healing by growth factors and cytokines. Physiol. Rev., v. 83, p. 835-870, 2003.

WINDLE, J. J.; SHIN, H. S.; MORROW, J. F. Induction of interleukin 1 messenger RNA and translation in oocytes. J. Immunol., v. 3, p. 263287, 1984.

WOJCIECHOWSKI, W.; DESANCTIS, J.; SKAMENE, E.; RADZIOCH, D. Attenuation of MHC class II Expression in Macrophages Infected with Micobacterium bovis BCG Involves class II Transactivator and Depends on the Nramp1 Gene. J. Immunol., v. 163, p. 2688- 2696, 1999.

WU, L.; FAN, J.; MATSUMOTO, S.; WATANABE, T. Induction and regulation of matrix metalloproteinase-12 by cytokines and CD40 signaling in monocyte/macrophages. Biochem. Biophys. Res. Commun., v. 269, n. 3, p. 808-815, 2000.

WYLLIE, P. S.; GOSS, J. A. The natural resistance-associated macrophage protein 1 Slc11a1 (formely Nramp1) and iron metabolism in macrophages. Microbes Infect., v. 4, p. 351-359, 2002. Review.

YU, H.; MOHAN, S.; MASINDE, G. L.; BAYLINK, D. J. Mapping the Dominant Wound Healing and Soft Tissue Regeneration QTL in MRL $X$ CAST. Mamm. Genome, v. 16, p. 918- 924, 2005. 